\title{
Degree of Conversion and Antibacterial Activity of Total-Etch Versus Self- Etch Adhesive Systems
}

\author{
Hamouda IM ${ }^{1,2 *}$, Beyari $M^{3}{ }^{3}$, Samra NA ${ }^{4}$ and Badawi MF \\ ${ }^{1}$ Dental Biomaterials Department, Mansoura University, Mansoura, Egypt \\ ${ }^{2}$ Conservative Dentistry Department, Umm Al- Qura University, KSA \\ ${ }^{3}$ Faculty of Dentistry, Umm Al-Qura University, Makkah, KSA \\ ${ }^{4}$ Faculty of Dentistry, Mansoura University, Egypt
}

\begin{abstract}
Objectives: This research was conducted to compare the degree of conversion and antibacterial activity of the total-etch (etch-and-rinse) versus self-etch adhesive systems.

Materials and methods: Degree of conversion was done using Fourier Transformation Infrared Spectroscopy. Uncured and cured specimens were prepared from each adhesive system and tested using potassium bromide disks The antibacterial activity of the adhesives was evaluated using agar disc-diffusion test against the following bacteria: Staphylococcus aureus, Streptococcus mutans and Lactobacillus salivarius obtained from soft carious dentin. Paper disks were coated with the tested adhesives and placed in the suitable growth media for each microorganism. The diameters of inhibition zones were measured at three different points. Sizes of inhibition zones were calculated by subtracting the diameter of the specimen from the average of the three measurements of the halo.
\end{abstract}

Results: G-Bond showed higher degree of conversion than that of Stae and Adper Prompt L-Pop adhesives. Adper Prompt L-Pop exhibited the highest antibacterial activity against $S$. mutans and S. aureus, while Stae exhibited the lowest antibacterial activity against $S$. mutans and $S$. aureus. All adhesives failed to demonstrate antibacterial activity against $L$. salivarius.

Conclusions: The tested adhesives showed degree of conversion with various percentages. All adhesives showed antibacterial action against $S$. aureus and S. mutans. On the other hand, they were failed to inhibit the growth of $L$. salivarius.

Keywords: Adhesive systems; Antibacterial activity; Degree of conversion; Self-etch; Total-etch

\section{Introduction}

True adhesion has been the "holy grail" of dental materials for many decades. True adhesion is the interdiffusion between the dentin of the tooth structure and the applied adhesive. If true adhesion of restorative materials to tooth structure is to be achieved, three conditions must be satisfied: sound tooth structure must be conserved, optimal retention must be achieved and microleakage must be prevented [1]. The foundation for modern adhesive dentistry was laid in 1955, when Bounocore reported that acids could be used to alter the surface of enamel to render it more receptive for adhesion. Since that time, dental adhesive systems have evolved through several generations with changes in chemistries, mechanisms, number of application techniques and clinical effectiveness [2]. Modern adhesive systems can be grouped into two categories according to their etching technique: total-etch and self-etch products [3]. The first category utilizes the total-etch (etchand-rinse) technique which relies on the removal of the smear layer and exposure of the collagen matrix by acid etching, followed by the application of a self-priming agent that combines the primer and the adhesive resin into one solution [4]. The second category utilizes the self-etch technique in which prior etching step is omitted. The selfetching products may be one-step or two-step self-etch adhesives. Twostep self-etch adhesives are characterized by utilizing a self-etching, hydrophilic primer that is followed by the application of a comparatively more hydrophobic bonding agent while the one-step self-etch adhesives contain two liquids which are applied to the tooth substrate after mixing. The latest approach in simplifying bonding to enamel and dentin are the adhesives in which all the adhesive components for etching, priming and bonding are supplied in a single bottle [5]. Degree of polymerization is one of the important factors that affect clinical performance of dental resins. Among several methods to determine the degree of conversion (DC), Fourier transformation infrared spectroscopy (FTIR) has been proven to be a powerful technique and has been widely used as a reliable method as it detects the $\mathrm{C}=\mathrm{C}$ stretching vibrations directly before and after curing of materials $[6,7]$. Dentin bonding systems which possess antibacterial properties would be beneficial in eliminating the harmful effect caused by bacteria. Among different methodologies used to determine the antibacterial activity of dentin bonding systems, simple direct inhibition tests such as agar-disc diffusion methods have been most frequently used $[8,9]$. This research was conducted to compare the degree of conversion and antibacterial activity of the total-etch (etch-and-rinse) versus self-etch adhesive systems.

\section{Materials and Methods}

The materials used in this test are listed in Table 1.

\section{Degree of conversion test (DC)}

Degree of conversion was done using Fourier Transformation

*Corresponding author: Ibrahim M. Hamouda, Conservative Dentistry Department, Umm Al- Qura University, KSA, Tel: +966542812148; E-mail imh100@hotmail.com

Received March 25, 2013; Accepted May 05, 2013; Published May 10, 2013

Citation: Hamouda IM, Beyari MM, Samra NA, Badawi MF (2013) Degree of Conversion and Antibacterial Activity of Total-Etch Versus Self-Etch Adhesive Systems. Clin Microbial 2: 113. doi:10.4172/2327-5073.1000113

Copyright: (c) 2013 Hamouda IM, et al. This is an open-access article distributed under the terms of the Creative Commons Attribution License, which permits unrestricted use, distribution, and reproduction in any medium, provided the original author and source are credited. 


\begin{tabular}{|c|c|c|c|}
\hline Materials & Composition & Batch Number & Manufacture \\
\hline $\begin{array}{l}\text { Stae (Fifth generation), Dentine/enamel, } \\
\text { 1-component adhesive }\end{array}$ & UDMA, Acetone fluoride stabilizer & 0406165 & SDI, Australia \\
\hline $\begin{array}{l}\text { Adper Prompt L-Pop (Sixth generation) } \\
\text { 2-component, single-step, self-etch adhesive }\end{array}$ & $\begin{array}{l}\text { Liquid } 1 \text { (red blister), Methacylated phosphoric, ester, Bis -GMA, Initiator, } \\
\text { based on comphorquinone , Liquid_2 (yellow blister),Water, 2-hydroxyethyl } \\
\text { methacrylate, Polyalkenoic acid Stabilizers_droxyethyl }\end{array}$ & 244893 & $\begin{array}{l}\text { 3M ESPE, St, Paul } \\
\text { MN,USA }\end{array}$ \\
\hline $\begin{array}{l}\text { G-bond (Seventh generation), 1-component, } \\
\text { single-step, self-etch adhesive }\end{array}$ & $\begin{array}{l}\text { 4-methacryloxyethyltrimelletic, acid (4- MET), Urethane, dimethacrylate (UDMA), } \\
\text { Phosphate monomer, Fused silica filler Photoinitiator, Acetone Stabilizer }\end{array}$ & 0506141 & GC Corp, Tokyo, Japan \\
\hline Glacier Microfilled hybride, composite & Multifunctional methacrylic, ester, Inorganic filler & 060273 & SDI, Australia \\
\hline
\end{tabular}

Table 1: Materials used in the study.

\begin{tabular}{|c|c|c|c|}
\hline Materials & Mean \pm SD & F-value & P-value \\
\hline Stae & $24.7^{\mathrm{B}} \pm 8.2$ & 28.8 & $<.001$ \\
\hline Adper Prompt & $23.2^{\mathrm{B}} \pm 3.9$ & & \\
\hline L-Pop & & & \\
\hline G-Bond & $49.6^{\mathrm{A}} \pm 11.1$ & & \\
\hline
\end{tabular}

Means with different superscripts are significantly different

Table 2: Mean degree of conversion and standard deviations of the three adhesives used in the study.

Infrared Spectroscopy (MATTERSON 500 FTIR Spectroscopy). Uncured specimen was taken from each bonding agent (Stae, Adper Prompt L-Pop and G-bond). Each uncured specimen was smeared onto a potassium bromide disk [6]. Nine cured specimens were prepared from each adhesive as follows: the occlusal enamel of the mandibular molar teeth was removed perpendicular to the long axis of the teeth with diamond burs under water-cooling to form a flat superficial, coronal dentin surface [6]. The adhesive was applied and cured according to the manufacturer's instructions for 20 seconds. Immediately after curing, the cured adhesive was scratched by a scalpel and changed into fine powder. Fifty micrograms of the powder was mixed with $5 \mathrm{mg}$ potassium bromide $(\mathrm{KBr})$ spectroscopic powder [10]. Each specimen was irradiated by the infrared spectrum of the FTIR Spectroscopy. The frequency of the infrared region used was between 4000 to $400 \mathrm{~cm}^{-1}$ wave number [6] and resolution was $4 \mathrm{~cm}^{-1}$.

The percentage of DC for each specimen was calculating from the following equation:

\section{$(\mathrm{C}=\mathrm{C} / \mathrm{C} \ldots \mathrm{C})$ after curing}

DC $\%=(1-$ ) X $100[10,11]$

\section{$(\mathrm{C}=\mathrm{C} / \mathrm{C} \ldots \mathrm{C})$ before curing}

$\mathrm{C}=\mathrm{C}$ is the aliphatic carbon=carbon bond; while $\mathrm{C}$....C is the aromatic carbon... carbon bond.

\section{Antibacterial activity test}

Although 200 to 300 bacterial species have been found in saliva, $S$. mutans has been considered as a potent caries causing bacteria. Saliva can act as a selective medium for bacterial growth, but continuously repeated swallowing results in clearing of bacteria. S. mutans is a facultative anaerobe and is a Gram-positive bacterium that lives in the mouth. It can thrive in temperature ranging from 18-40 degrees Celsius. It metabolizes different kinds of carbohydrates, creating acidic environment in the mouth as a result of this process. This acidic environment in the mouth is what causes the tooth decay. It is the leading cause of dental caries (tooth decay) worldwide. S. mutans is considered to be the most cariogenic of all of the oral Streptococci [12]. S. aureus belongs to the family Staphylococcaceae. It affects all known mammalian species, including humans. The microscopic appearance of $S$. aureus is round and resembles that of a sphere (cocci). Grampositive cocci in clusters. Because of the way the bacteria divide and multiply, it will appear in clusters or tetrads. L. salivarius is a grampositive, non-spore forming bacillus bacteria. It is a homofermentative organism (only produces one byproduct of metabolism-lactic acid) that is found occurring naturally in the human oral cavities. L. salivarius is a facultative anaerobe, meaning that it can grow in the presence or absence of oxygen [13].

The antibacterial activity of the adhesives was evaluated using agar disc-diffusion test against the following bacteria: Staphylococcus aureus, Streptococcus mutans and Lactobacillus salivarius. This study was conducted in the Medical Diagnostic and Infection Control Unit (MDICU) at the Microbiology \& Immunology Department, Faculty of Medicine, Mansoura University.

\section{Sample collection}

Random samples of soft carious dentin were directly taken from carious cavities by a sterile excavator from randomly selected patients [14]. S. aureus, S. mutans, and L. salivarius were isolated, incupated and identified by means of the strain morphology, microscopic examination and biochemical reactions.

\section{Preparation of the tested materials}

Paper disks were used to be coated with the tested adhesives. These disks were prepared as follows: filter paper was punched using a hole punch to make small circular paper discs. These disks were wrapped in aluminum foil and sterilized in the hot air oven at $160^{\circ} \mathrm{C}$ for $30 \mathrm{~min}$ $[15,16]$. Twenty $\mu$ l of each adhesive were impregnated into a sterile paper disk (diameter: $6 \mathrm{~mm}$, thickness: $1.5 \mathrm{~mm}$ ) and cured for 20 seconds. A $20-\mu \mathrm{l}$ volume was chosen as the optimum for impregnation into paper disk without overflow of the tested materials [17]. The antibacterial effect was evaluated using the disk diffusion method: culture medium was Muller-Hinton agar for S. aureus, blood agar for $S$. mutans and rogosa agar for $L$. salivarius. The paper disks containing the tested materials were seated on the sterile Petri dish at equal distances from each other by applying firm pressure to the disks with a sterile forceps against the medium surface, 3 disks per dish. Each plate was labeled with the names of the tested materials and microorganisms, and incubated at $37^{\circ} \mathrm{C}$ for $24 \mathrm{~h}$ in the case of S. mutans and S. aureus [18] and at $35^{\circ} \mathrm{C}$ for 3 days in case of L. salivarius [19]. The diameters of inhibition zones were measured at three different points. Sizes of inhibition zones were calculated by subtracting the diameter of the specimen from the average of the three measurements of the halo [20]. 
Citation: Hamouda IM, Beyari MM, Samra NA, Badawi MF (2013) Degree of Conversion and Antibacterial Activity of Total-Etch Versus Self-Etch Adhesive Systems. Clin Microbial 2: 113. doi:10.4172/2327-5073.1000113

Page 3 of 7

\section{Statistical analysis}

One-way ANOVA test was used to analyze the data obtained by the tested adhesives. The least significant difference (LSD) statistical test was used to detect the significant differences between the tested groups.

\section{Results}

\section{Degree of conversion (\%)}

Mean DC (\%) and standard deviation for Stae, Adper Prompt L-Pop and G-Bond are presented in Table 2. G-Bond had the highest mean DC $(\%)$ value $(\mathrm{P}<0.05)$, while Adper Prompt L-Pop and Stae had similar values.
Graphical presentations of the absorbance peaks for uncured and cured Stae, uncured and cured Adper Prompt L-Pop and uncured and cured G-Bond are shown in Figures 1-6: respectively. For Stae, the absorbance peaks of the infrared rays for the aliphatic $\mathrm{C}=\mathrm{C}$ of the monomer was $1635 \mathrm{~cm}^{-1}$ and $1636 \mathrm{~cm}^{-1}$ for the uncured and curd resin respectively. The absorbance peaks of infrared rays for aromatic C...C of the monomer for uncured and cured resin were $1534 \mathrm{~cm}^{-1}$ and $1537 \mathrm{~cm}^{-1}$ respectively.

For Adper Prompt L-Pop, the absorbance peaks of the infrared rays for the aliphatic $\mathrm{C}=\mathrm{C}$ of the monomer was $1635 \mathrm{~cm}^{-1}$ and $1636 \mathrm{~cm}^{-1}$ for the uncured and curd resin respectively. The absorbance peaks of infrared rays for aromatic C...C of the monomer for uncured and cured resin were $1512 \mathrm{~cm}^{-1}$ and $1512 \mathrm{~cm}^{-1}$ respectively.

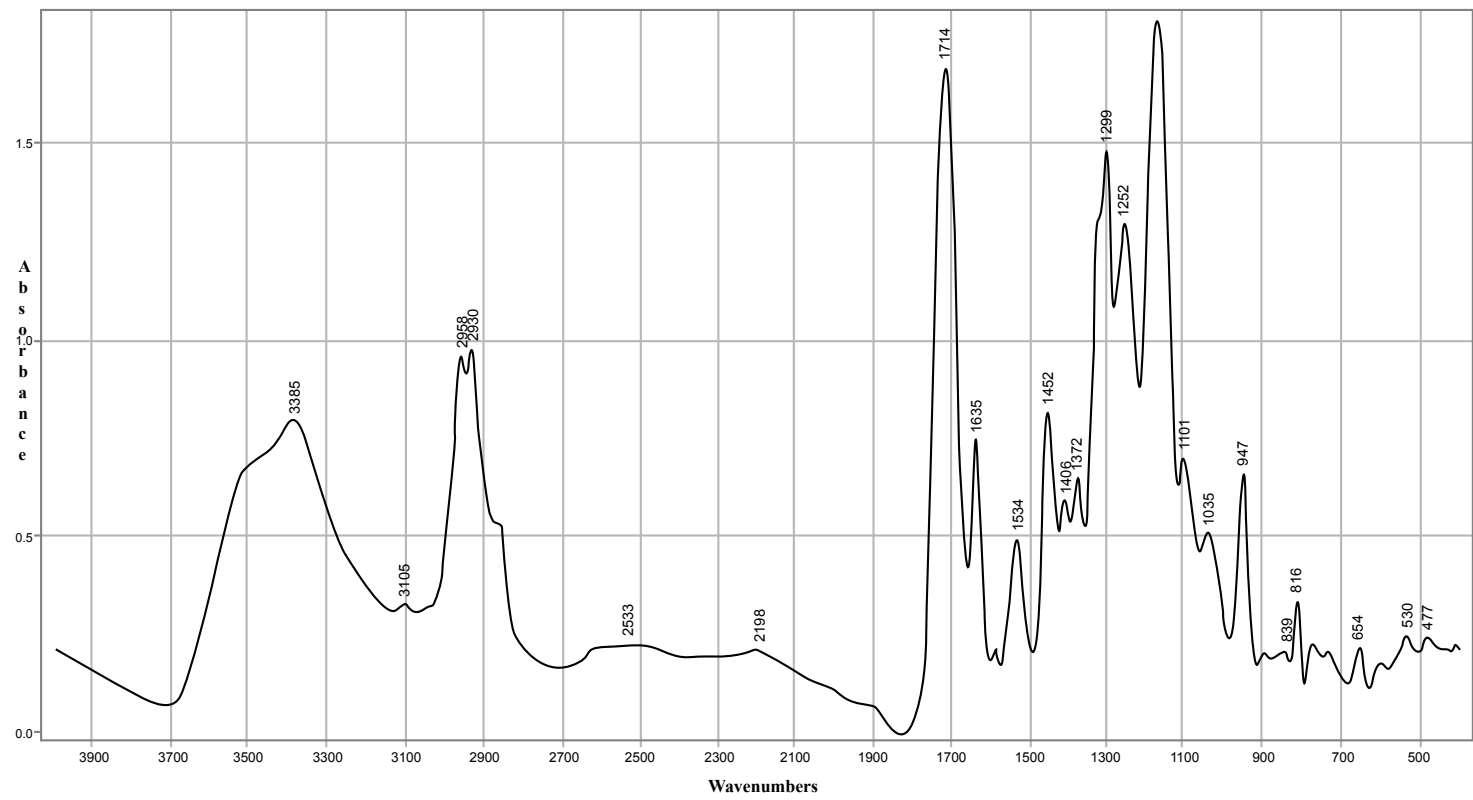

Figure 1: The absorbance peaks of the infrared rays by $\mathrm{C}=\mathrm{C}$ and $\mathrm{N} \ldots \mathrm{H}$ in the monomer of the uncured adhesive resin of Stae.

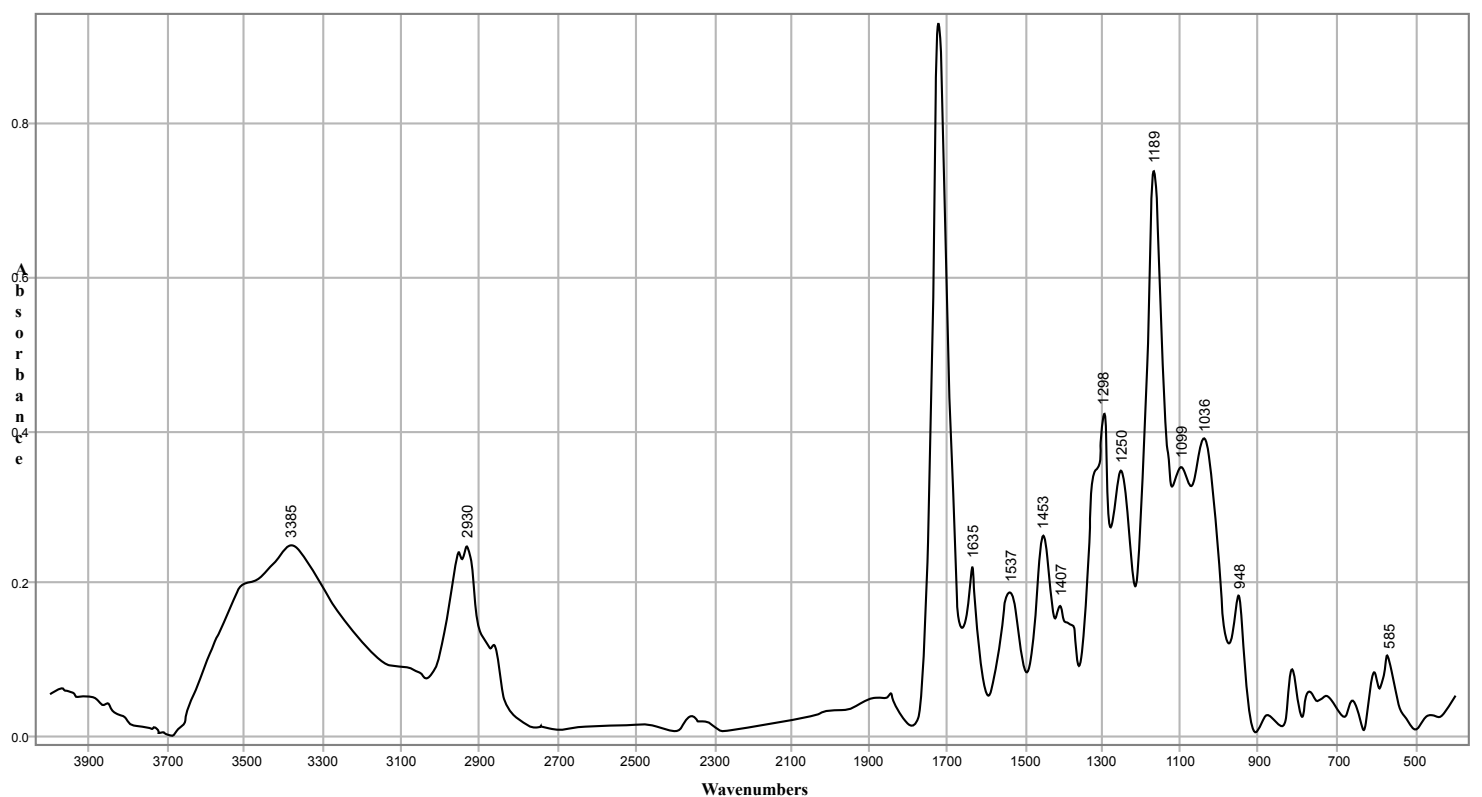

Figure 2: The absorbance peaks of the infrared rays by $\mathrm{C}=\mathrm{C}$ and $\mathrm{N} \ldots \mathrm{H}$ in the monomer of the cured adhesive resin of Stae. 
Citation: Hamouda IM, Beyari MM, Samra NA, Badawi MF (2013) Degree of Conversion and Antibacterial Activity of Total-Etch Versus Self-Etch Adhesive Systems. Clin Microbial 2: 113. doi:10.4172/2327-5073.1000113

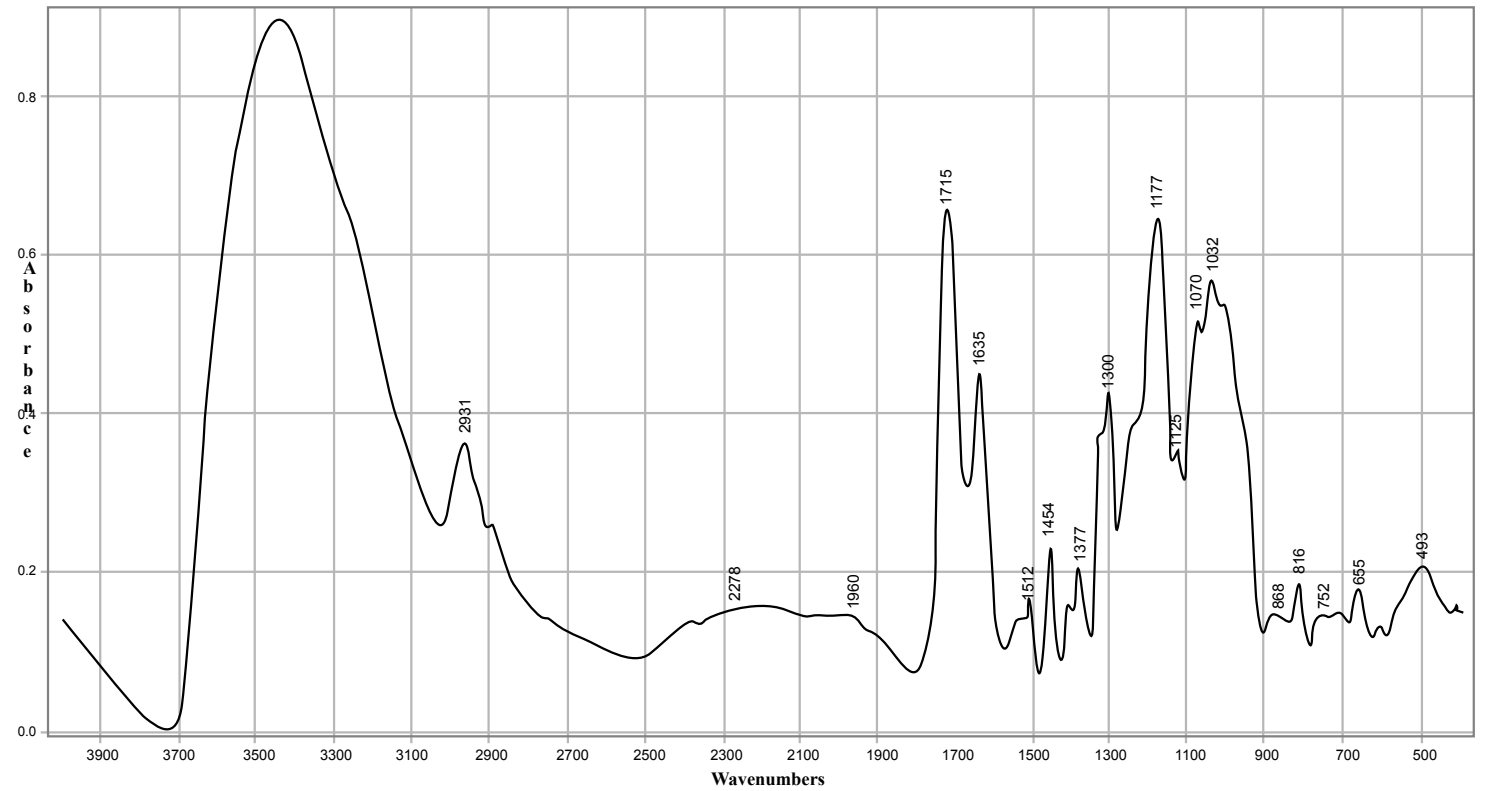

Figure 3: The absorbance peaks of the infrared rays by $\mathrm{C}=\mathrm{C}$ and $\mathrm{C} \ldots \mathrm{C}$ in the monomer of the uncured adhesive resin of Adper Prompt L-Pop.

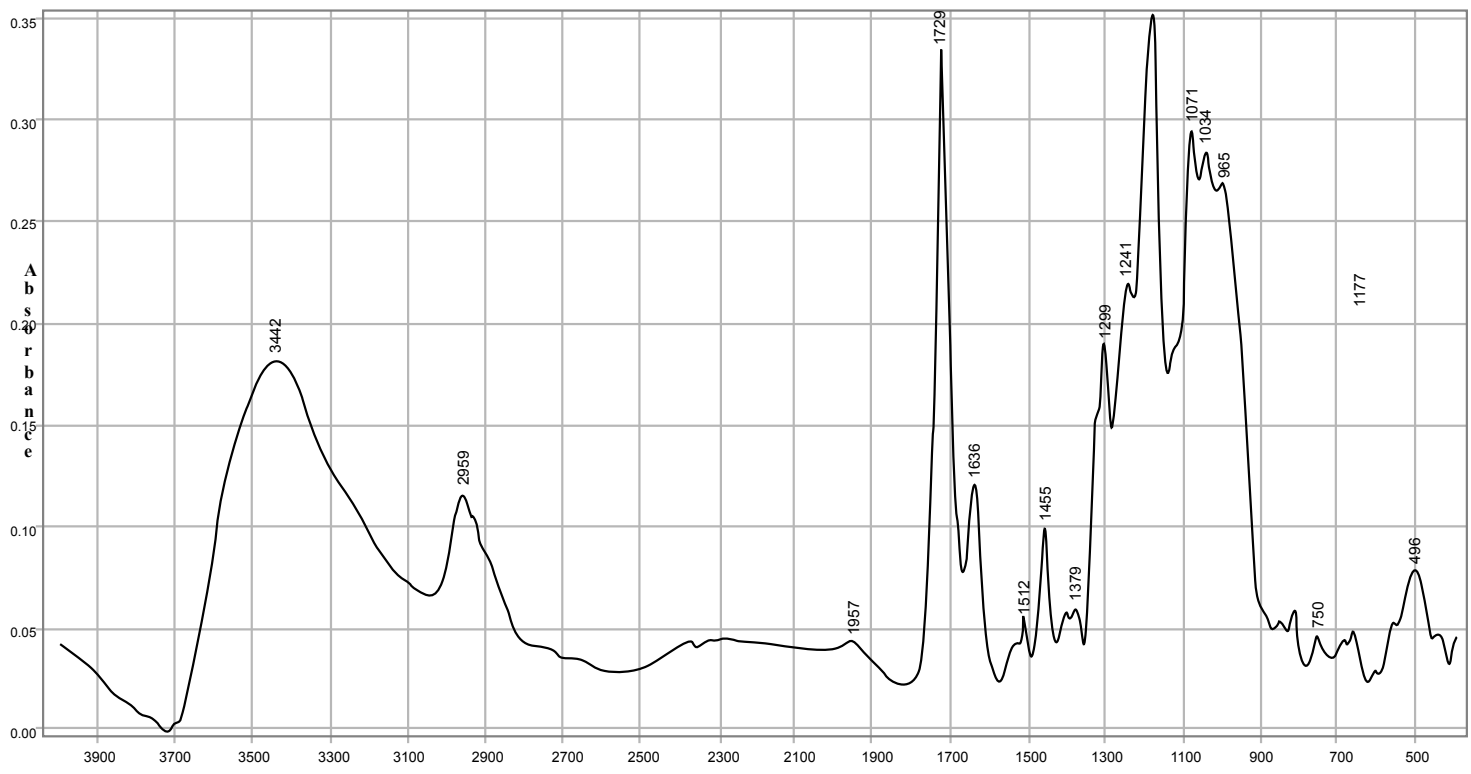

Figure 4: The absorbance peaks of the infrared rays by $C=C$ and $C . . . C$ in in the monomer of the cured adhesive resin of Adper Prompt L-Pop.

For G-Bond, the absorbance peaks of the infrared rays for aliphatic $\mathrm{C}=\mathrm{C}$ of the monomer was $1637 \mathrm{~cm}^{-1}$ and $1639 \mathrm{~cm}^{-1}$. The absorbance peaks of aromatic C....C of the monomer for uncured and cured resin were $1532 \mathrm{~cm}^{-1}$ and $1538 \mathrm{~cm}^{-1}$ respectively.

\section{Antibacterial activity test}

Mean inhibitory zones and standard deviations for all adhesives are presented in Table 3. Graphical presentations of inhibitory zones are shown in Figures 7-9. Stae, Adper Prompt L-Pop and G-Bond demonstrated growth inhibition against $S$. mutans and $S$. aureus and no inhibition was observed against $L$. salivarius.

Significant differences were observed between all adhesives
$(\mathrm{P}<0.05)$, with Adper Prompt L-Pop exhibiting the highest mean inhibitory zones and Stae the lowest.

\section{Discussion}

The current interest in dentin bonding research is focused on reducing the number of application steps in the bonding procedures providing simpler and faster adhesives and reducing the technique sensitivity as well as operator variability [6]. The constant development in adhesive restorative dentistry has already caused profound changes in dental practice, and future advances such as one-step self-etching systems have been proposed as suitable agents for dentin bonding. They combine the three steps of etching, priming and bonding in a single application [21]. 


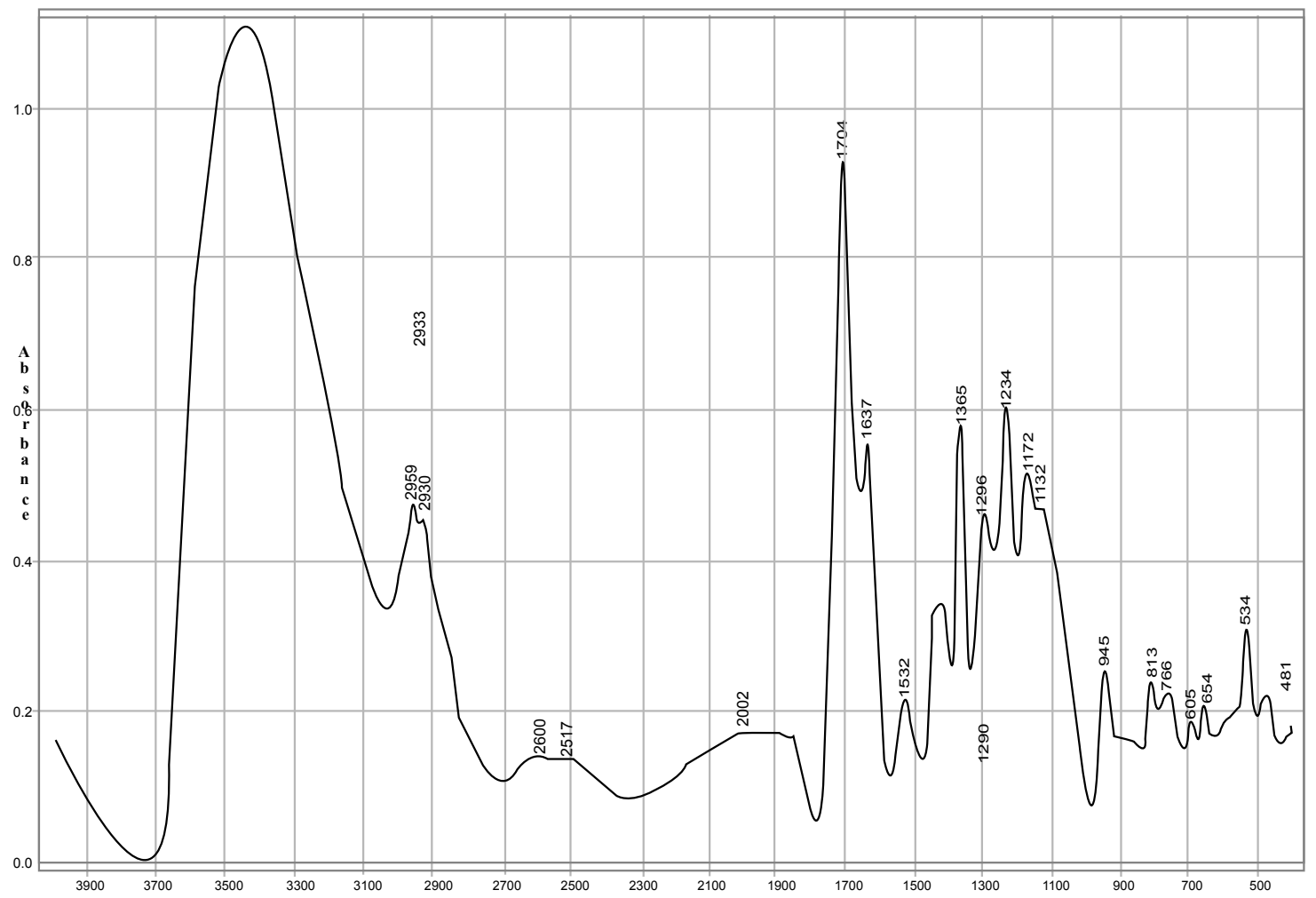

Figure 5: The absorbance peaks of the infrared rays by $\mathrm{C}=\mathrm{C}$ aWev\$umpdrin the monomer of the uncured of G-Bond adhesive resin.

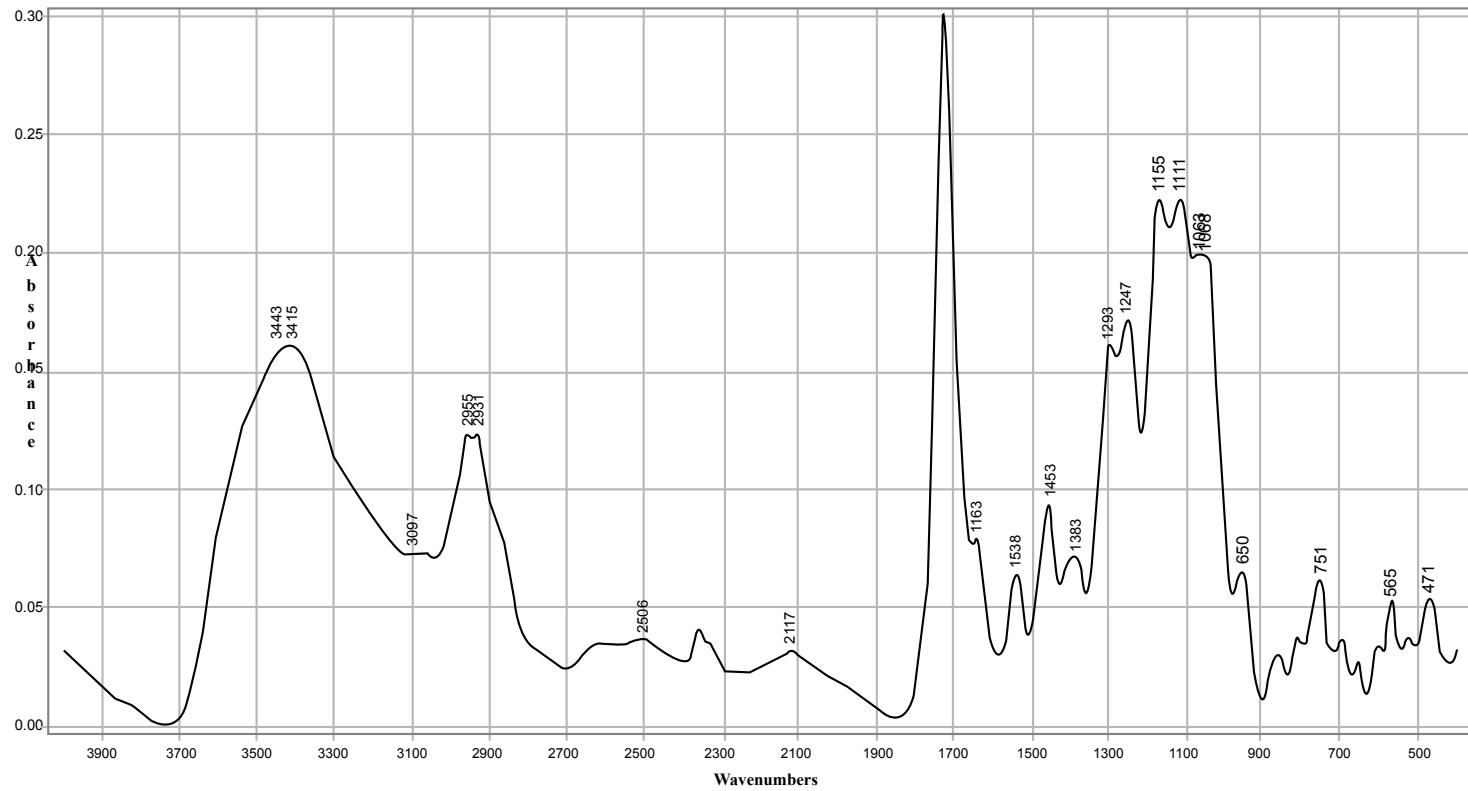

Figure 6: The absorbance peaks of the infrared rays by $\mathrm{C}=\mathrm{C}$ and $\mathrm{N} \ldots \mathrm{H}$ in the monomer of the cured of G-Bond adhesive resin

HEMA, hydrophilic primer is commonly included in the adhesive system to improve the bond strength. On the other hand HEMA lowered the vapor pressure of water when added to water, making it more difficult to remove water from the adhesive and retaining water within the adhesive layer. The results showed that G-bond had the highest mean degree of conversion value of the adhesives used in the study and this difference was statistically significant. The high results of G-bond may be attributed to the fact that it is HEMA-free one-step self-etch adhesives.

The improved results of the Stae adhesive may be attributed to the 
Citation: Hamouda IM, Beyari MM, Samra NA, Badawi MF (2013) Degree of Conversion and Antibacterial Activity of Total-Etch Versus Self-Etch Adhesive Systems. Clin Microbial 2: 113. doi:10.4172/2327-5073.1000113

acetone content of the adhesive .The role of acetone in the bonding solution is to lower the viscosity of the solution, so enhancing the penetration of the bonding agents into the demineralized collagen-rich dentin matrix, and to lower the surface tension of water due to "water chasing" effect. Moreover, acetone may increase the vapor pressure of water and enhance the removal of collagen matrix water, which may then be exchanged for the acetone and ultimately for the adhesive resin [22].

Complete sealing at the bonded interface is a prerequisite for successful restorations [23]. It is well recognized that residual bacteria after removal of a carious lesion causes increased pulp sensitivity, pulpal inflammation and secondary caries [15]. Additionally, microleakage of bacteria through the gap between the restoration and the cavity

\begin{tabular}{|c|c|c|c|}
\hline Materials & S. mutans & S. aureus & L. salivarius \\
\hline Stae & $0.5^{\mathrm{C}} \pm 0.3$ & $1.61 \pm 1.08^{\mathrm{C}}$ & 0 \\
\hline Adper Prompt & & & \\
\hline L-Pop & $1.82^{\mathrm{A}} \pm 0.8$ & $4.23 \pm 1.26^{\mathrm{A}}$ & 0 \\
\hline G-Bond & $0.91^{\mathrm{B}} \pm 0.7$ & $1.81 \pm 1.46^{\mathrm{B}}$ & 0 \\
\hline F-value & 5.46 & & \\
\hline P-value & $0.02^{*}$ & & \\
\hline LSD & 0.91 & & \\
\hline
\end{tabular}

Means with different superscripts are significantly different

Table 3: Mean inhibitory zones $(\mathrm{mm})$ and slandered deviations of the bonding agents.

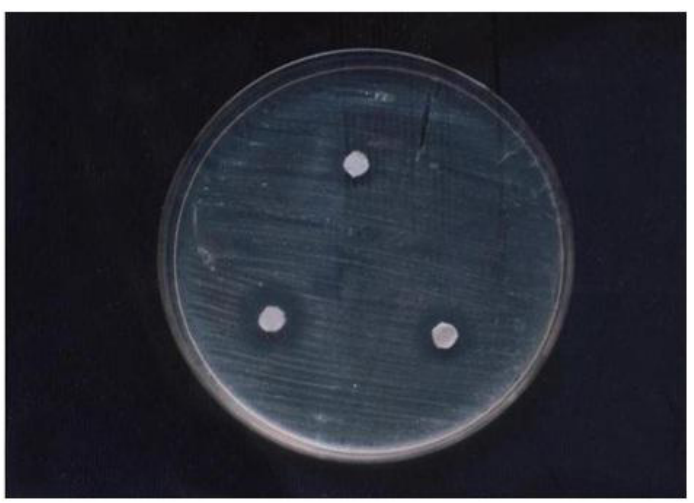

Figure 7: Photographs showing the inhibitory zones of Stae $(A)$, Adper Prompt L-Pop (B) and G-Bond (C) against streptococci.

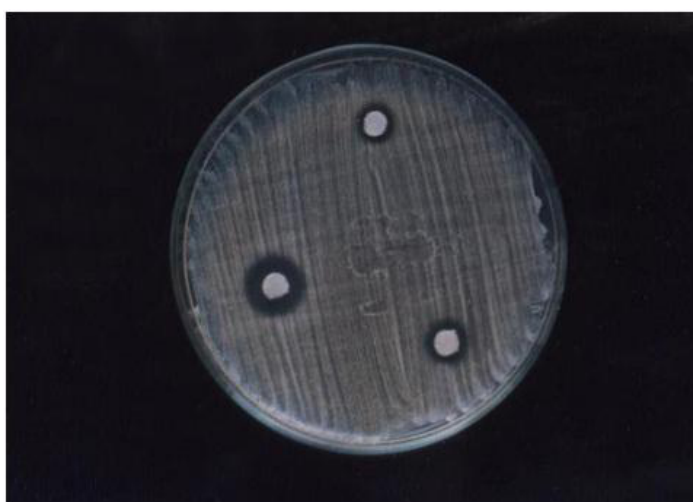

Figure 8: Photographs showing the inhibitory zones of Stae (A), Adper Prompt L-Pop (B) and G-Bond (C) against staphylococci.

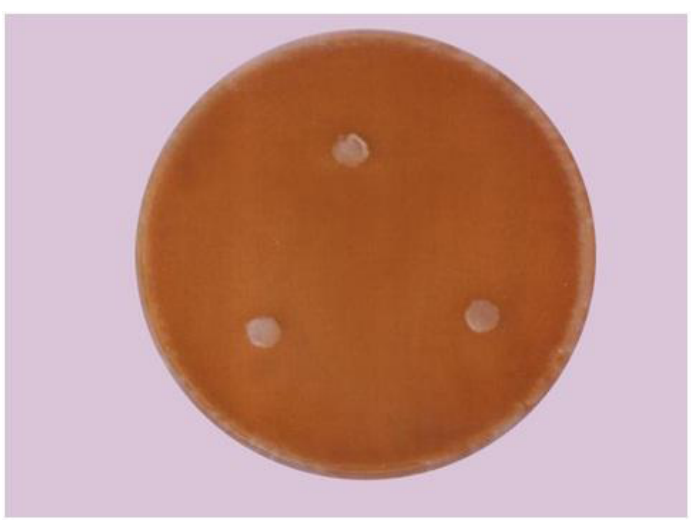

Figure 9: Photographs showing the inhibitory zones of Stae (A), Adper Prompt L-Pop (B) and G-Bond (C) against lactobacilli.

wall in known to be the main cause of unpleasant symptoms, which occur after placement of restorations. However, even dentin adhesive systems which show high bond strength have been reported to be incapable of preventing the occurrence of microgaps between the tooth and the restoration in vitro $[23,15]$. Secondary caries, whether the result of bacterial invasion through microleakage or from residual bacteria left in the cavity preparation, has consistently been found to be the most common reason for the replacement of amalgam and composite restorations [7]. Therefore, dentin bonding systems which posses antibacterial activity even after placement in the cavity would be beneficial for eliminating the harmful effect caused by bacterial micro leakage [23]. S. mutans and S. sobrinus are associated with the initiation of human dental caries, while $L$. salivarius is associated with the progression of the established lesion [7]. Agar-disc diffusion test method is a simple direct inhibition test and it has been most frequently used [9]. Addition of acidic monomers in large amounts for self-etching adhesive systems to promote adhesion, decrease $\mathrm{pH}$ values of these materials enough to kill or at least inactivate the bacteria [9]. The antibacterial effect shown by dentin bonding agents in this study may be related to their $\mathrm{pH}$ [7]. The $\mathrm{pH}$ of the bonding agents used in the study are Prompt L-Pop ( $\mathrm{pH} 0.7)$ [17], G-Bond ( $\mathrm{pH}$ $>2.0$ ) [24] and Stae ( $\mathrm{pH} 0.5$ ) [8]. The self-etching adhesives used in this study have demonstrated antibacterial action to varying degrees. In what regards Adper Prompt L-Pop and G-Bond, antibacterial activity was shown against $S$. mutans and $S$. aureus but failed to demonstrate antibacterial action against $L$. salivarius. These results can be explained on the basis of the previous observation which attributed this effect to low $\mathrm{pH}$ values of these materials. However the lower inhibitory effect against $L$. salivarius may attribute to the acid tolerance of such species [8]. As regard to total-etch systems, Stae has demonstrated antibacterial action against $S$. mutans and $S$. aureus but to lesser degrees and failed to demonstrate antibacterial action against $L$. salivarius. This effect could be compensated by the antibacterial effect of its etchant which is applied on the cavity walls before applying the stae adhesive as a part of totaletch protocol. Etching of the dentinal surface with acidic solution, such as phosphoric acid, during the bonding procedures may be effective to reduce the number of residual bacteria in the cavity [25].

\section{Conclusions}

Within the limitations of this research, the following conclusions were conducted.

1. The degree of conversion values for the 1-component selfetch adhesives (G-Bond) were significantly higher than that 
Citation: Hamouda IM, Beyari MM, Samra NA, Badawi MF (2013) Degree of Conversion and Antibacterial Activity of Total-Etch Versus Self-Etch Adhesive Systems. Clin Microbial 2: 113. doi:10.4172/2327-5073.1000113

of 2-component total-etch and self-etch adhesives tested (Stae\& Adper Prompt L-Pop).on the other hand, there was no significant difference between 2-component total-etch and selfetch adhesives tested (Stae\& Adper Prompt L-Pop).

2. Two-component self-etch adhesives (Adper Prompt L-Pop) exhibited the highest antibacterial activity against $S$. mutans and $S$. aureus, while 2-component total-etch adhesives (Stae) exhibited the lowest antibacterial activity against $S$. mutans and S. aureus.

3. One-component self-etch adhesives (G-Bond) exhibited antibacterial activity against $S$. mutans and $S$. aureus which was significantly different with Stae in case of $S$. mutans. G-Bond wasn't significantly different with Stae in case of $S$. aureus.

4. All the tested adhesives failed to demonstrate antibacterial activity against $L$. salivarius.

\section{References}

1. Anusavice KJ. Philips, Science of Dental Materials, 11th edition. Philadelphia WB Saunders, 2003, pp. 381-396.

2. Stalin A, Varma BR; Jayanthi (2005) Comparative evaluation of tensile-bond strength, fracture mode and microleakage of fifth, and sixth generation adhesive systems in primary dentition. J Indian Soc Pedod Prev Dent 23: 83-88.

3. YeÄŸilyurt C, Bulucu B (2006) Bond strength of total-etch and self-etch dentin adhesive systems on peripheral and central dentinal tissue: a microtensile bond strength test. J Contemp Dent Pract 7: 26-36.

4. Proença JP, Polido M, Osorio E, Erhardt MC, Aguilera FS, et al. (2007) Dentin regional bond strength of self-etch and total-etch adhesive systems. Dent Mater 23: 1542-1548.

5. Frankenberger R, Tay FR (2005) Self-etch vs etch-and-rinse adhesives: effect of thermo-mechanical fatigue loading on marginal quality of bonded resin composite restorations. Dent Mater 21: 397-412.

6. KnezeviÄ $\ddagger$ A, Tarle Z, Meniga A, Sutalo J, Pichler G, et al. (2001) Degree of conversion and temperature rise during polymerization of composite resin samples with blue diodes. J Oral Rehabil 28: 586-591.

7. Imazato S, McCabe JF, Tarumi H, Ehara A, Ebisu S (2001) Degree of conversion of composites measured by DTA and FTIR. Dent Mater 17: 178-183.

8. Karanika-Kouma A, Dionysopoulos P, Koliniotou-Koubia E, Kolokotronis A (2001) Antibacterial properties of dentin bonding systems, polyacid-modified composite resins and composite resins. J Oral Rehabil 28: 157-160.

9. Imazato S (2003) Antibacterial properties of resin composites and dentin bonding systems. Dent Mater 19: 449-457.

10. Tarumi H, Imazato S, Ehara A, Kato S, Ebi N, et al. (1999) Post-irradiation polymerization of composites containing bis-GMA and TEGDMA. Dent Mater 15: $238-242$

11. Hashimoto M, Tay FR, Svizero NR, de Gee AJ, Feilzer AJ, et al. (2006) The effects of common errors on sealing ability of total-etch adhesives. Dent Mater 22: $560-568$.

12. Ohalete CN, Obiukwu CE, Uwaezuoke JC, Dozie INS, Nwaehiri UL (2012) Epidemiological studies on dental caries in imo state Nigeria. World Journal of Pharmacy and Pharmaceutical Sciences 1: 1158-1170.

13. Grey WT, Curtiss R 3rd, Hudson MC (1997) Expression of the Streptococcus mutans fructosyltransferase gene within a mammalian host. Infect Immun 65 2488-2490.

14. Imazato S, Torii Y, Takatsuka T, Inoue K, Ebi N, et al. (2001) Bactericidal effect of dentin primer containing antibacterial monomer methacryloyloxydodecylpyridinium bromide (MDPB) against bacteria in human carious dentin. J Oral Rehabil 28: 314-319.

15. Johnson T, Case C, 1995. "Chemical methods of control". Adapted from Laboratory Eperiments in Microbiology, Brief edition, 4th ed, Redwood city, CA: BenjaminlCummings puplishing. www.sciencebuddines.org/cience.fair projects/projectideas. (accessed June,2007)

16. Takahashi Y, Imazato S, Kaneshiro AV, Ebisu S, Frencken JE, et al. (2006) Antibacterial effects and physical properties of glass-ionomer cements containing chlorhexidine for the ART approach. Dent Mater 22: 647-652.

17. Imazato S, Kuramoto A, Takahashi Y, Ebisu S, Peters MC (2006) In vitro antibacterial effects of the dentin primer of Clearfil Protect Bond. Dent Mate 22: $527-532$.

18. Cheesbrough M. District Laboratory Practice in Tropical Countries, pp. 157165. Cambridge University Press, Cambridge.

19. Sharpe ME. Selective media for the isolation and enumeration of lactobacilli. Lab.Practice1960; 9: 223-227.

20. Johnson T, Case C, 1995 "Chemical methods of control" Adapted from Laboratory Eperiments in Microbiology, Brief edition, 4th ed, Redwood city CA: BenjaminlCummings puplishing.www.sciencebuddines.org/cience.fair projects/projectideas. (accessed June,2007).

21. Yoon TH, Lee YK, Lim BS, Kim CW (2002) Degree of polymerization of resin composites by different light sources. J Oral Rehabil 29: 1165-1173.

22. Hiraishi N, Breschi L, Prati C, Ferrari M, Tagami J, et al. (2007) Technique sensitivity associated with air-drying of HEMA-free, single-bottle, one-step selfetch adhesives. Dent Mater 23: 498-505.

23. Imazato S, Kinomoto Y, Tarumi H, Ebisu S, Tay FR (2003) Antibacterial activity and bonding characteristics of an adhesive resin containing antibacteria monomer MDPB. Dent Mater 19: 313-319.

24. Pashley DH, Sano H, Ciucchi B, Yoshiyama M, Carvalho RM (1995) Adhesion testing of dentin bonding agents: a review. Dent Mater 11: 117-125.

25. Khosravi K, Mousavi M (2005) Effect of pre-etching on sealing ability of two current self-etching adhesives. J Research in Medical Sciences 10:150-155. 